\title{
Hacia una transformación de la legislación penal
}

Abogado de la Universidad de Medellín, especializado en Instituciones Jurídicos Penales Universidad Nacional-Surcolombiana. Catedrático de la Universidad Surcolombiana.

\section{Gustavo Méndez Salazar}

$\mathrm{R}$

ecién nos adaptamos a las leyes 599 y 600 del año 2000 , conociendo sus bondades y deficiencias cuando ya se anuncian cambios a la legislación penal, incluyendo reforma de la Fiscalía con la introducción del SISTEMA ACUSATORIO, anunciado en la Constitución Política vigente (1991) y aún así, estamos como al principio: improvisando.

Hoy nos encontramos ad portas de una nueva reforma penal y procesal penal, pero nuestrás preocupaciones no cesan ante la posibilidad de enfrentar una nueva, pero similar situación. Justo es traer a colación las palabras del inmolado jurista Jesús María Valle Jaramillo, cuando a raíz de la entrada en vigencia del Decreto 1853 de 1985, donde por primera vez se pretendía consagrar en Colombia el SISTEMA ACUSATORIO expresó: - Hasta que en el país no seamos capaces de realizar una reforma penal en el contexto de nuestra idiosincrasia y cultura social, económica y política, nunca acabaremos con la impunidad; los modelos foráneos e impuestos sin consultar esos elementos tan nuestros, sin lugar a dudas, siempre fracasarán".
Nada más cierto, pues en verdad las leyes colombianas no consultan nuestra idiosincrasia, sino ıque se inspiran en patrones foráneos y por lo tanto, no son eficaces; con frecuencia ensayamos nuevos modelos que no satisfacen nuestras necesidades jurídicas.

Hoy, ante la inminente reforma penal èn tránsito en el Congreso, no cesan las preocupaciones por cuanto seguimos convencidos que antes que imposiciones jurídicas, debemos revisar las condiciones y aspectos culturales y con base en ellos, estructurar nuestro auténtico y propio sistema jurídico.

Tal reforma se fundamenta en el significativo hecho de que las anteriores, no han colmado las expectativas en torno a la realización del objetivo buscado y menos han contribuido decididamente a resolver los múltiples problemas que inciden en la realización y materialización de la justicia penal. Factores tales como la lentitud en los trámites procesales, costos de los procesos y los demasiados e innecesarios formalismos y en fin, tantos otros aspectos que incentivan la

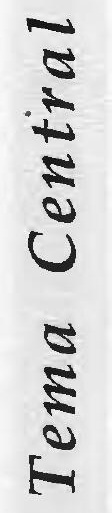


impunidad, como grave y complejo resultado ante la inoperancia de todos aquellos elementos que integran el proceso de administrar justicia.

A raî̉z de la Asamblea Nacional Constituyente, la Constitución de 1991 establece en nuestro país el sistema acusátorio y no faltan quienes lo denominan híbrido debido a su mezcla con el inquisitivo; de ahí que antes de estructurar un verdadero sistema procesal penal, ágil, garantista y en un marco de verdad acusatorio surge por creación constitucional la Fiscalía General de la Nación, donde en realidad lo que hubo solo fue un cambio de nombre frente a las actividades de lo que otrora se conocía como Jueces de Instrucción Criminal, dado que el procedimiento continuaba igual, es decir, mixto con tendencias a inquisitivo.

Se propende por instaurar un sistema de pofítica criminal, garantista de Estado, fo que conlleya a establecer o estructurar nuevos códigos penal y de procedimiento penal, haciendo acopio de de técnica legislativa en dicho ámbito, en concordancia con los adelantos de la tecnología al igual que de la ciencia penal moderna.

Lamentablemente, el concepto de política criminal garantista de Estado no han sido bien entendido en su real dimensión y en cambio en la práctica solo se trata de ligerezas conceptuales.

Es de resaltar como meritoria de la última reforma, la labor de recopilar toda la legislación penal y procesal dispersa en varias leyes tanto ordinarias como de excepción, situación demostrativa de la inflación legislativa y de improvisación histórica en este campo. No obstante, hay que reconocer que tal codificación permitió a los operadores judiciales, por lo menos conocer cual norma era aplicable a un caso concreto.

Como ha sido consuetudinaria en nuestro medio, la terquedad del legislador y la forma inconsulta y casi clandestina como se desarrollaron los debates de los proyectos, impidió se presentaran y tuvieran en cuenta diversas opiniones en torno a la inoperancia de los. sistemas propuestos. Así las cosas, se produce el mismo tipo de legislación, es decir, continua operando el procedimiento mixto con tendencia acusatoria ya que en realidad y ante la ausencia de una verdadera metodología y línea directriz, señalada por un interés nacional y no personal, que cayó en el mismo esquema que se pretendía reformar. Esto por cuanto en la práctica siguió el modelo procesal anterior sin que en verdad se presentaran auténticos y significativos cambios en torno a figuras diferentes estructuralmente, en verdaderos sistemas acusatorios, como:

1. La presunción de inocencia: Excepto que anteriormente operaba únicamente al momento de proferir fallo operando así para todo el proceso, más solo en la teoría, nunca en la realidad práctica.

2. Facultades judiciales a la Fiscalía: Convirtiéndola así en juez y parte, pues al fin y al cabo participa de la rama judicial.

3. El derecho a la libertad: Continua siendo la excepción, pues en un sistema acusatorio la libertad es la 
norma general y así debe ser por cuanto carece de sentido privar de la libertad al implicado para investigarlo y a la postre, no obstante al no poder probar algo, tener que dejarlo en libertad cuando ya purgó una pena anticipada, sin haber sido vencido en juicio; en verdad, lo procedente y fundamental es primero investigar antes de privar de la libertad, pues de esa manera se realizan o se materializan los demás principios garantes de un proceso penal realmente democrático.

4. La investigación penal: Sin que pudiera entenderse como hacía el fiscal para investigar lo favorable y lo desfavorable al implicado o sindicado, según se trate de indagación previa o preliminar o de investigación formal, dejando de lado la polarización material de los sujetos procesales propios de un sistema diferente, donde se acusa o no se acusa; y el mismo listado de conductas punibles, excarcelables o no entre otras.

De la anterior reseña es apreciable que todo concluyó en vanos intentos, aunque de buena fe, por mejorar el sistema, pero ante la ausencia de consulta y confrontación de los proyectos con la academia, la misma judicatura, la colectividad profesional, conllevó a que se perdiera valioso tiempo, en lo que otrora ha debido abordar sin temores y tapujos, debiendo asumir con seriedad convicción y claridad la estructuración de un verdadero sistema acusátorio no sin tener en cuenta aspectos tales como los culturales, sociales, económicos y políticos más relevantes de nuestra cultura. Mientras eso no ocurra, no es posible pensar seriamente en resolver la problemática histórica de la justicia penal en nuestro país.

\section{El sistema acusatorio}

Entendiéndolo como el máximo modelo de expresión de una sociedad democrática en el contexto de una política criminal de Estado -abolicionista, logrando del derecho penal en la realidad la última ratio del Estadodinamizador de una justicia garantista, siendo incuestionable que las reformas por adelantar no pasarán de ser más que paños de agua tibia, caracterizando cada vez más compleja, caótica y diff́til de contener, como hasta ahora lo ha sido nuestra administración de justicia.

Históricamente el sistema acusatorio ha sido construido basado en principios tales como:

1. El derecho a la libertad: Siendo ésta la norma general, más no la excepción; contrario a lo que en la práctica sucede en nuestro actual sistema.

2. La presunción de inocencia: Más no de responsabilidad como está consagrado en nuestras normas.

3. Respeto a la dignidad humana: Destacando que un ciudadano, por más avezado delincuente que sea, tiene derechos que hay que reconocer y respetar.

4. Etapa investigativa separada de juzgamiento: Con responsabilidad asignada a entes diferentes: Fiscalía, jueces y jurados populares.

5. Facultades jurisdiccionales únicamente en cabeza del juez: No aún en el fiscal como sucede actualmente.

6. Debido proceso: Caracterizado por el respecto de las garantías que ilustran y 
estructuran un proceso verdaderamente justo y democrático.

7. Oralidad, publicidad, inmediación, contradicción probatoria, principio de oportunidad, etc.: No es posible perder de vista que tanto nuestros legisladores como los sucesivos gobiernos, nunca han mostrado interés por estos aspectos, siendo por demás demostrativo de las calidades culturales, sociales y políticas de una sociedad.

A pesar del tiempo perdido amén de las incongruencias conceptuales y políticas, ha sido presentado un nuevo proyecto de acto legislativo, que pretende reformar principalmente la Constitución Política, en lo que concierne a artículos atenientes al funcionamiento de la Fiscalía General de la Nación y el sistema penal, propugnando por un sistema acusatorio puro a imitación o fiel copia del modelo norteamericano, esperanzados a que tal sistema tenga un adecuado y oportuno desarrollo legal.

El acto legislativo 003 del 19-XII-2002 Consagra una reforma integral del viejo sistema, estructurando desde la base constitucional, un autentico sistema acusatorio, el cual gira entorno a cinco grandes ejes a saber:

1. Oralidad: Reforma el Art. 250 de la Carta Magna; principio necesario y fundamental, medular del sistema acusatorio, en procura de lograr acabar con la mora y lentitud en la administración de justicia, pero para ello, se requiere de una adecuada dotación técnico-logística. Esto conlleva, por su misma naturaleza, principios como el de inmediación, publicidad y controversia probatoria en el marco de celeridad y garantías en su debido contexto en pro de la realización del valor justicia.

2. Supresión de facultades jurisdiccionales a la Fiscalía, creando el juez de control: Resuelve de una vez lo que implica que un organismo judicial fuese juez y parte en un mismo proceso, contrariando los más elementales principios procedimentales penales, donde el juez se elige como el verdadero catalizador y garantizador de los derechos ciudadanos-y garante de una justicia realmente justa.

3. Principio de oportunidad: Con base en todos los poderes que actualmente tiene el fiscal, éste puede, en determinadas circunstancias abstenerse de adelantar una investigación amparado en la insignificancia del hecho o su intrascendencia y hasta la conmoción social del mismo.

4. Jurados populares: En este aspecto se concreta el sueño de una verdadera y autentica justicia, de carácter popular no elitista, donde el ciudadano construye sociedad en virtud del ejercicio de juez popular de sus pares, donde el Estado debe ser garante y protector, proporcionando la logística para que los ciudadanos puedan ejercer tales funciones. El jurado popular es una gran conquista de la humanidad y la mayor manifestación de una sociedad democrática, aunque dado el caos reinante no deja de suscitar temores, pero no demos temerle al cambio por el que necesariamente hay que pagar cuotas de sacrificio en tratándose de lograr condiciones mejores para el mismo desarrollo social en la que todos estamos empeñados sin olvidar que la 
justicia es determinante en la construcción social.

5. Creación de un Sistema Nacional de Defensoría Pública: Buscando equilibrio entre la acusación y la defensa, sin olvidar que la mayoría de quienes incurren en conductas punibles carecen de recursos económiços pará asegurar su defensa, siendo responsabilidad del Estado implementar la Defensoría Pública, destinando grandes recursos humanos, técnicos y económicos, etc; y así garantizar el derecho a la igualdad de todos ante la ley, desenvolviéndose 60 en un plano de
igu a 1 d a d
social, lo
cual es
determinante
para lograr
una adecuada
realización del
sistema.

En síntesis

Con base en los aspectos destacados, necesario estructurar un cambio de modelo institucional y constitucional, logrando la creación, implementación y adecuado funcionamiento de un nuevo sistema procesal penal, moderno, de avanzada que consulte nuestra idiosincrasia para que contribuya a hacer realidad la solución de los grandes y complejos problemas que tiempo atrás nos aquejan, buscando que no se repita la historia $y$ al fin, los colombianos podamos contar con verdaderos operadores jurídicos, que actúen en un marco de garantías y respecto por la dignidad humana en pos de lograr la materialización del valor de:justicia como factor medular de la construcción q de una s o c i e d a d Ligualitaria, W/Solidaria y verdaderamente j u s t a, logrando al fin un desarrollo sostenible en medio de un clima de hermandad $y$ solidaridad, donde todos tengamos cabida y se respeten los derechos de todos. 